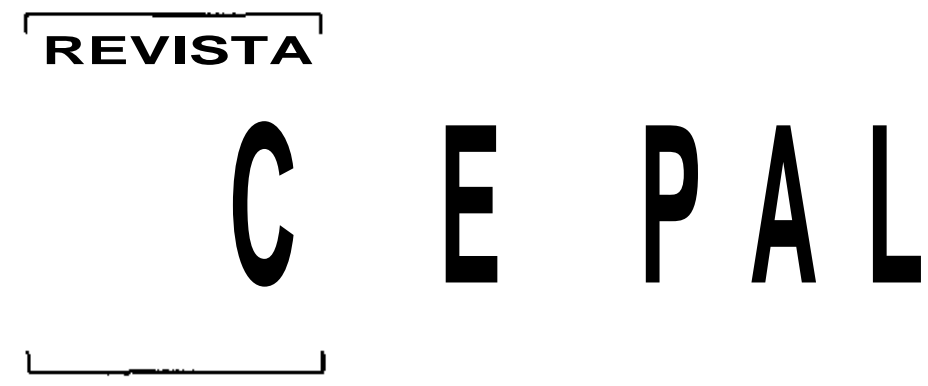

NUMERO 65

AGOSTO 1998

SANTIAGO DE CHILE

OSCAR ALTIMIR

Director

EUGENIO LAHERA

Secretario Técnico

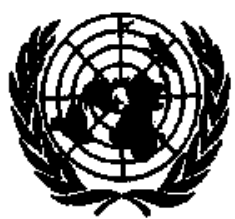

NACIONES UNIDAS 
Distribución del ingreso, pobreza y gasto social en América Latina José Antonio Ocampo

Gasto militar y el desarrollo en América Latina

Eugenio Lahera y Marcelo Ortúzar

Crecimiento, justicia distributiva y política social

Andrés Solimano

Equidad, inversión extranjera y competitividad internacional

Adolfo Figueroa

Tensiones en el ajuste estructural en América Latina: asignación Ms. distribución

Daniel M. Schydlowsky

Competitividad y regulaciones laborales

Luis Beccaria y Pedro Galín

Familias latinoamericanas: convergencias y divergencias de modelos y políticas

Irma Amagada

Los acuerdos de libre comercio y el trabajo de las mujeres:

el caso de Chile

Alicia Frohmann y Pilar Romaguera

Evolución macroeconómica del Paraguay 1989-1997:

burbuja de consumo y crisis financiera

119 L.-

Stéphane Straub

Estrategias de las empresas mexicanas en sus procesos de internacionalización 133

Alejandra Salas-Porras

La regulación de la prestación privada de servicios de agua potable y alcantarillado

Terence R. Lee y Andrei S. Jouravlev

Promoción de la calidad para mejorar la competitividad

Hessel Schuurman

Publicaciones recientes de la CEPAL 


\section{Promoción de}

\section{Hessel Schuurman}

Ex Experto Asociado ONUDI/CEPAL,

División de Desarrollo

Productivo y Empresarial, CEPAL

\section{la calidad para mejorar la competitividad}

El autor se propone demostrar la importancia que reviste la calidad para las estrategias nacionales dirigidas a mejorar la productividad y la competitividad en América Latina. En mercados cada vez más globalizados y liberalizados, la calidad es fundamental y, por lo tanto, la aplicación estratégica de técnicas de gestión de la calidad ayuda significativamente a mejorar el desempeño competitivo de los países, los sectores económicos y las organizaciones. Puesto que la competitividad contribuye al desarrollo sostenible, convendría difundir tales técnicas y aplicarlas ampliamente desde una perspectiva nacional. Últimamente los gobiernos latinoamericanos han puesto en marcha numerosos programas para promover y apoyar la (difusión de las técnicas de gestión de la calidad. Ảsí, este tema tendrá una incidencia cada vez mayor en los objetivos de desarrollo social y económico de los países de la región. Se observa, sin embargo, que la introducción de innovaciones en materia de gestión total de !a calidad no ha sido fácil ni rápida: por ejemplo, en América Latina las normas iso 9000 para los sistemas de calidad no se han difundido con la misma celeri-, dad que en otras regiones del mundo. Para el autor, el nivel de conciencia de la calidad en la región se ha visto afectado por las características de los mercados, las dificultades de acceso a los recursos, las prácticas de gestión tradicionales y las condiciones macroeconómicas, factores que pueden vincularse con las disfunciones de mercado que se producen dentro de las empresas, entre éstas y en los mercados de factores. En conse cuencia, varios gobiernos han optado por promover las técnicas de gestión de calidad para realizar los ajustes necesarios ante las fallas de mercado. El artículo concluye con una reseña de las actividades realizadas en algunos países de América Latina para intensificar la difusión de los sistemas de gestión de la calidad establecidos en las normas iso 9000 . 


\section{I}

\section{Introducción}

Se entiende por calidad de un producto o servicio el conjunto de propiedades y características que le confieren la aptitud para satisfacer necesidades expresas o implícitas. En consecuencia, la gestión de la calidad en una organización entraña la internalización del concepto de "satisfacción del cliente". Además, como los defectos de calidad pueden mermar considerablemente los recursos de una organización y reducir su rendimiento, el logro de la calidad entrañará el "perfeccionamiento continuo" de las actividades de la organización que incidan en la calidad, El resultado de este perfeccionamiento puede ser una mejor calidad de los productos, menos desperdicio y menos reprocesamiento o mejores condiciones de trabajo en las actividades secundarias. Es más, en lo que toca a asegurar calidad al cliente se ha pasado de la sola inspección del producto final al control de los procesos operativos, y luego al de la fase de diseño del proceso o producto. En consecuencia, la gestión de la calidad no es un asunto secundario que atañe exclusivamente a departamentos especializados de una organización, sino que tiene que ver con la gestión de la organización en su conjunto.

La gestión total de la calidad es una concepción de la gestión que apunta a mejorar el rendimiento de una empresa cumpliendo ciertos objetivos vinculados con la satisfacción del cliente y el mejoramiento continuo. En la gestión total de la calidad se hace hinca- pié, entre otras cosas, en la utilización de métodos de medición y seguimiento, el mejoramiento de las comunicaciones entre las distintas áreas funcionales y de las relaciones, el cumplimiento de las normas de calidad y el desarrollo de los recursos humanos (Rauter, 1992). A fin de que una organización sea eficaz (dé satisfacción al cliente) y eficiente (esté en mejoramiento continuo), se ha elaborado y aplicado una amplia gama de técnicas de gestión de la calidad que incorporan los principios de gestión total de la calidad recién enunciados. Estos principios pueden orientar la aplicación de las diversas técnicas de gestión en la materia.

La calidad se ha convertido en uno de los aspectos fundamentales de la competencia que impera en ios mercados en esta época de globalización y liberalización, por lo que la aplicación de la gestión de la calidad contribuye eficazmente a lograr un desempeño competitivo. La competitividad puede definirse como la capacidad de un país o de una organización de generar proporcionalmente más riqueza que sus competidores en el mercado mundial, como señala The World Competitiveness Report dc 1995.' En las dos secciones siguientes se examinarán diversos aspectos de la gestión de calidad y la competitividad en los planos nacional, sectorial y empresarial.

\section{II \\ Gestión de la calidad y competitividad en los planos nacional y sectorial}

A nivel nacional, la competitividad puede analizarse aplicando el enfoque utilizado en el World Competitiveness Repon. En su versión de 1995 este informe incluye una lista de 48 países, clasificados según su nivel dc competitividad, calculada utilizando factores como la solidez de la economía nacional, la aplicación de políticas de gobierno propicias, la infraestructura existente, etc. Siguiendo la metodología del informe, los aspectos vinculados con la calidad se incluyen de preferencia en el factor "gestión" (o sea, si las empre- sas se administran con criterios innovadores, rentables y responsables) y, en menor medida, en el factor "ciencia y tecnología" y el factor "humano" (o sea, la capacidad científica y tecnológica y los resultados obtenidos mediante la investigación básica y aplicada; y la disponibilidad de recursos humanos y su nivel dc capacitación). La calidad puede considerarse entonces como

\footnotetext{
${ }^{1}$ Foro Económico Mundial, Instituto Internacional para el Desarrollo de la Capacidad dc Gestión, 1995.
} 
un factor que contribuye a la competitividad de un país. ${ }^{2}$ Por ejemplo, se ha determinado que las técnicas de gestión de la calidad han contribuido significativamente al éxito económico de las empresas japonesas pues permiten que sus procesos de producción sean más flexibles, productivos y competitivos.

En el gráfico 1 se muestra la relación entre la gestión total de la calidad y la competitividad. En el eje de las abscisas se indica el código de los países clasificados en función de su competitividad global, conforme a los cálculos consignados en el World Competitiveness Report de 1995, Se solicitó a los directivos de empresas de todos los países participantes que evaluaran el uso de la gestión total de la calidad en su país mediante una escala de uno a diez. Los resultados se indican en el eje de las ordenadas. La tendencia global (media lineal) de la relación entre la gestión total de la calidad y la competitividad indica que en los países que se consideran más competitivos se está aplicando cada vez dicha gestión. ${ }^{3}$ La relación no lineal entre la competitividad y la gestión total de la calidad obedece a que indudablemente esta última no es el único factor que determina la competitividad internacional.

GRAPICO I

\section{Gestión integral de la calidad y} competitividad

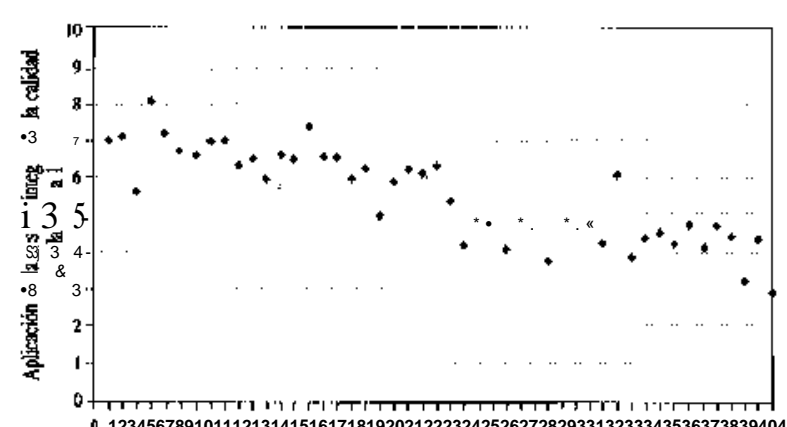
Código de país en la clasificación según el nivel de competitividad

\footnotetext{
2 A fin de determinar la medida en que la calidad contribuye a la competitividad, el autor ha analizado las cifras que figuran en los cuadros del World Competitiveness Repon y ha estimado que los factores vinculados con la gestión de la calidad pueden contribuir aproximadamente en un $12 \%$ al valor total asignado a la competitividad de los países en la clasificación mencionada. Nótese que esta cifra es el resultado de un ejercicio muy rudimentario y por lo tanto es simplemente indicativa.

${ }^{3}$ El lector puede encontrar los nombres de los países que corresponden a los códigos utilizados en el gráfico 1 en la publicación del Foro Económico Mundial, Instituto Internacional para el Desarrollo de la Capacidad de Gestión, 1995, o en el artículo publicado por Schuurman (1997a).
}

El mejoramiento del desempeño competitivo global de los sectores económicos de un país no se limita a determinadas empresas de esos sectores. También es el resultado de aplicar la gestión de calidad en toda la cadena de producción y de suministro de bienes. Por ejemplo, en el desempeño competitivo de una empresa puede influir el desempeño competitivo de sus proveedores o de otros subcontratistas y de la mayor o menor comunicación con éstos (constituido por los eslabonamientos ascendentes y descendentes entre los mismos sectores o entre sectores conexos). Por lo tanto, en las teorías sobre el desarrollo industrial competitivo se hace hincapié en la promoción de la reorganización dentro de la empresa y la creación de redes empresariales. La Organización de Cooperación y Desarrollo Económicos señala que el éxito económico de tales redes empresariales no se ha debido al acceso ventajoso a factores de producción, como mano de obra, capitales y/o tierra baratos, sino a una organización económica y social muy eficaz de dichas redes (OCDE, 1993).

Los principios de la gestión total de la calidad que parecen contribuir en mayor medida a la internalización de los problemas de calidad en la cadena de producción son los siguientes: la comunicación y difusión de información, la medición y el seguimiento y el cumplimiento de estándares de calidad. ${ }^{4}$ A fin de enfrentar las presiones crecientes que impone la competitividad global, las grandes empresas definen sus áreas básicas de actividad (conforme a sus ventajas competitivas) y con frecuencia subcontratan o tercerizan todas las demás. De este modo, las grandes empresas comienzan a depender cada vez más de los proveedores y, en consecuencia, tratan de asegurarse de que éstos sean confiables, de mejorar la comunicación y de establecer relaciones duraderas con ellos. Mediante la internalización de la gestión de calidad en la cadena de producçión se podrá, entre otras cosas, reducir el costo de las transacciones, lograr mayor flexibilidad e introducir innovaciones en materia de calidad en todo un sector económico, contribuyendo así a mejorar su desempeño competitivo. Por ejemplo, la empresa Xerox (fotocopiadoras) capacitó a determinados proveedores en los métodos de procesos estadísticos y en las técnicas de gestión de calidad operacional. Merced a ello, en un período de dos años los costos netos de producción se redujeron en $10 \%$, el volumen de productos que

\footnotetext{
${ }^{4}$ La medida en que el rubro calidad contribuye a la competitividad de los sectores industriales puede determinarse mediante el análisis de la competitividad desarrollado por Porter, 1980.
} 
no cumplían con las especificaciones disminuyó en 93\% y el costo del desarrollo de nuevos productos y el tiempo empleado en ello se redujeron en $50 \%$ (Burnt, 1990).

\section{III}

\section{Gestión de la calidad y competitividad a nivel de empresas}

El factor decisivo en la competitividad de una empresa es su capacidad para integrar el mejoramiento de la calidad (fundamental para lograr la satisfacción del cliente) con medidas dirigidas a aumentar la rentabilidad (que interesa a los directivos). En las economías abiertas, las empresas relativamente más competitivas amplían su participación en el mercado porque los consumidores están satisfechos con determinadas características de sus productos o servicios. ${ }^{5}$ La satisfacción del cliente puede vincularse con uno o más atributos de los productos o servicios provistos por una organización (Pandora, I989), a saber:

i) Un precio razonable: el precio del producto debería adecuarse a la necesidad que de él tiene el cliente.

ii) Un producto bueno: la calidad del producto debe ser confiable o cumplir con especificaciones predeterminadas,

iii) Un plazo de entrega razonable: el cliente debe recibir el producto en un plazo determinado, de lo contrario el producto no tiene ningún valor.

iv) Un producto único en su género: todos aspiran a adquirir un producto o servicio que sea algo distinto o que satisfaga estrictamente las necesidades personales. Esto exige que los fabricantes sean capaces de satisfacer esa demanda de productos diversos.

v) Un producto nuevo: los consumidores cambian los productos viejos que poseen las características enunciadas por otros mejores, más rápidos, que estén de moda, más modernos, más resistentes, que contengan los materiales más modernos, etc.

En consecuencia, el desempeño competitivo de las empresas en los mercados de consumo (globales) estará determinado por su capacidad de atender simultá-

\footnotetext{
5 La satisfacción del consumidor reviste especial importancia en los mercados en que la oferta supera la demanda. En los mercados globales, prácticamente saturados de productos y servicios, los consumidores pueden elegir lo que desean.
}

neamente a los factores que inciden en la competencia, como la eficiencia, la calidad, los plazos de entrega, la flexibilidad y la capacidad innovadora (Fleury, 1995; Maas, 1992; Pandora, 1989). ${ }^{6}$ Veremos a continuación que es posible aplicar técnicas de gestión de calidad a cada uno de los factores que inciden en la competencia. Dicho en forma más sencilla, es posible que para lograr mayor competitividad baste que la empresa aplique el concepto de mejoramiento continuo a los parámetros que determinan los factores de competencia pertinentes.

\section{Eficiencia: un precio razonable}

En tanto factor de competencia, la eficiencia o el precio exigen que la función de producción —es decir, la relación matemática entre las cantidades de insumos y productos- sea lo más eficiente posible en función del costo. Por ejemplo, la optimización del capital y de la productividad del trabajo han llevado a introducir economías de escala con las que se trata de lograr el máximo de eficiencia reduciendo ai mínimo los costos de producción unitarios. Con respecto a la gestión de la calidad y la eficiencia se podría pensar, entre otras cosas, en minimizar el volumen de materiales de desecho y la cantidad de unidades del producto que no cumplen con las especificaciones, disminuir los tiempos de espera (tiempos muertos) de los materiales y productos y reducir el volumen de existencias (de materiales o productos).

Para aumentar ¡a eficiencia de la producción se han aplicado diversos conceptos de gestión. Los de principios del siglo XX son bien conocidos y se utili-

\footnotetext{
${ }^{6}$ Es preciso tener en cuenta que si bien los factores enunciados se analizan en función de su evolución en el tiempo, están estrechamente vinculados entre sí. Por ejemplo, la aplicación de técnicas que aseguren la calidad y las innovaciones puede aumentar la eficiencia, en tanto que la reducción de los plazos de entrega puede ser el resultado de una mayor flexibilidad.
} 
zan ampliamente. En ellos, el proceso de producción se organiza mediante una división pormenorizada del trabajo. Cada empleado contribuye al proceso realizando una subtarea determinada en la línea de montaje. Aunque estos procedimientos "taylorístas" o "fordistas" han permitido aumentar la eficiencia considerablemente, también han establecido en el ámbito laboral una división entre el "pensar" y el "hacer". La organización de la parle "pensante" ha generado una gran pirámide jerárquica de responsabilidades y relaciones de poder, característica de las prácticas de gestión tradicionales. En el contexto de esta estructura piramidal, el producto llega al consumidor después de atravesar los diversos departamentos funcionales. En cada departamento los supervisores de distintas jerarquías adoptan decisiones vinculadas con sus propias responsabilidades funcionales sin preocuparse mayormente por las consecuencias que pueden tener esas decisiones para otros departamentos, para el cliente u otros usuarios finales. Por ejemplo, al departamento de producción le preocupa más lograr que el costo de producción unitario sea bajo, que las posibles pérdidas por concepto de almacenamiento si la producción es excesiva.

Leñero (1995) estima que en tales marcos de organización funcional el tiempo total que transcurre desde que se inicia el proceso de generación del producto hasta que éste llega al consumidor (también llamado tiempo muerto) es entre uno a dos veces mayor que la duración real de las tareas necesarias para realizar el proceso. En otras palabras, el tiempo muerto de un producto puede oscilar entre un $100 \%$ y un $200 \%$. Hammer y Champy (1993) han descrito acertadamente tales ineficiencias, proponiendo "repensar a fondo y rediseñar radicalmente los procesos empresariales a fin de mejorar notablemente las mediciones actuales más decisorias del rendimiento como son los costos, la calidad, los servicios y la rapidez". El rediseño de los procesos se centra en los más importantes con límites funcionales entrecruzados y va más allá del mero perfeccionamiento de los procesos existentes, pues se plantea permanentemente si es necesario realizar tal o cual tarea, y de serlo, con qué tipo de organización y participación laboral debería realizarse. La reingeniería surgió a raíz de que las nuevas aptitudes con que debe contar la fuerza de trabajo y las expectativas crecientes de los consumidores han vuelto inoperante la división entre "el pensar y el hacer" (MacDonald, 1995). El segundo factor que se vincula con frecuencia con la reingeniería es la modernización mediante la aplicación de tecnologías de punta en el campo de la in- formación, las comunicaciones, las telecomunicaciones y la organización. Evidentemente, las medidas que se adopten para mejorar la competitividad deberán incluir tanto las innovaciones en materia de organización como tecnológicas. ${ }^{7}$

A fin de lograr el mejoramiento continuo la mayoría de las empresas se concentran en los procesos y métodos internos. Sin embargo, se pueden utilizar técnicas de comparación de prácticas para determinar la posición de la empresa en relación con las empresas rivales que aplican las innovaciones más recientes (en materia de gestión de la calidad). Hay dos formas de comparar prácticas. En la primera se centra la atención en el producto, analizando las formas de reducir costos mediante la evaluación de los productos y servicios. En la segunda se centra la atención en los procesos, examinando los de producción y de gestión. En términos generales, mediante las técnicas de comparación de prácticas, que entrañan la búsqueda de oportunidades en el medio en que se desenvuelve la empresa, se ha logrado aumentar la eficiencia y reducir los costos (Zairi, 1996). Si se aplica la comparación de prácticas centrada en los procesos dentro de un marco de gestión total de la calidad puede mejorarse la eficiencia de la organización en lo que toca a la satisfacción del cliente y el perfeccionamiento permanente.

El término "redimensionamiento" se refiere a la eliminación de determinadas funciones o áreas que no son parte de las competencias básicas de la empresa o no le aportan ventajas competitivas de significación. Por las presiones de la competencia, las empresas se especializan en las actividades que realizan mejor y subcontratan las actividades conexas (tercerización). El término "desestratificación" se refiere a la reducción del número de niveles jerárquicos $\mathrm{y}$, tal como la reducción de escala y la tercerización, puede contribuir a aumentar la eficiencia y la flexibilidad.

Cabe señalar que la reingeniería, la actualización, el redimensionamiento, la tercerización y la desestratificación se orientan a menudo a mejorar la eficiencia a través de cambios organizacionales básicos. Procesos de esta índole pueden dar resultado en el corto plazo y por lo general entrañan reducciones de personal. Sin embargo, se dice que la proporción de empresas que no han aplicado los principios de la reingeniería ni mejorado la eficiencia excede el 30\% (Champy,

\footnotetext{
${ }^{7}$ El presente análisis se limitará al primero de los aspectos enunciados. Sin embargo, muchas innovaciones organizacionales incidirán en las innovaciones tecnológicas, y viceversa.
} 
1995). En la bibliografía especializada muchos autores coinciden en que es preciso aplicar simultáneamente los principios de la reingeniería con los de la gestión total de la calidad. ${ }^{8}$ A este respecto, se recomienda que todo cambio organizacional vaya acompañado del desarrollo de los recursos humanos. Estas actividades son fundamentales si se desea asegurar que se comprendan los nuevos principios organizacionales y las tecnologías.

\section{Calidad: un buen producto}

Los principios de la gestión total de la calidad pueden orientar la aplicación de prácticas de gestión a todos los factores de la competencia mencionados. Así, los conceptos fundamentales de la gestión total de la calidad y las técnicas de gestión de calidad constituyen el núcleo de la competitividad a nivel de empresas. En un estudio realizado en 700 empresas de Europa occidental (KID, 1996) se informa que aquellas que han implantado eficazmente los principios de la gestión total de la calidad han logrado: aumentar el nivel de satisfacción de los clientes y la participación del personal; tomar mayor conciencia de la importancia de la calidad; reducir los costos y mejorar el rendimiento.

Por lo general, la gestión de la calidad entraña la planificación, el control y el mejoramiento sistemáticos de la calidad mediante el diseño de una estructura organizacional adecuada en la que puedan aplicarse las técnicas de gestión de la calidad y a la que se puede denominar sistema de gestión de la calidad. Los sistemas de esta índole comprenden la estructura organizacional, las responsabilidades, y los procedimientos, procesos y recursos para aplicar la gestión de calidad. En las normas internacionales iso 9000 se definen diversos modelos de garantía de calidad para los sistemas de gestión de la calidad. Por ejemplo, en la norma iso 9001 se fijan 20 requisitos que caracterizan un sistema de calidad y abarcan las etapas de diseño, producción e inspección final. La verificación de que un sistema cumple con la norma iso 9001 puede estar a cargo de un tercero acreditado. La certificación de este tipo de sistema se produce luego de una auditoría de certificación realizada por terceros. Las auditorías de gestión de la calidad, tanto internas como externas, son prácticas habituales. Cuando se ha certificado que una empresa cumple con las normas iso 9000 ésta puede hacer uso de esa condición para promocional ${ }^{1}$ sus

\footnotetext{
${ }^{8}$ Véase, por ejemplo, MacDonald (1995) y Leñero (1995).
}

productos o servicios entre sus clientes. La implementación de un sistema de calidad que cumpla con las normas iso 9000 debe considerarse como un paso intermedio y útil para alcanzar la gestión total de la calidad (Q Review, 1993). En las cadenas de producción o redes de empresas las normas iso 9000 se ajustan a los requisitos de ios regímenes de garantía de calidad centrados en los procesos. Varias encuestas realizadas en empresas a las que se ha otorgado una certificación conforme a las normas iso 9000 permiten concluir que entre un $65 \%$ y un $75 \%$ de ellas alientan a sus proveedores y subcontratistas a que también la obtengan. Estos argumentos explican, en parte, la relación entre las normas iso 9000 y la competitividad (Schuurman, 1997a).

En vista de la tendencia a tercerizar determinadas actividades, resulta cada vez más importante para las organizaciones asegurar o garantizar a sus clientes que están en condiciones de cumplir con ciertos estándares de calidad preestablecidos. Para reducir los costos de transacción, las empresas han ido abandonando los regímenes de garantía de la calidad centrados en el producto (inspección final) y han adoptado regímenes centrados en las normas de gestión de la calidad. En tal sentido las que han alcanzado mayor aceptación son las normas iso 9000 . Este hecho refleja que se acepta como válida la hipótesis de que una buena gestión de la calidad en los procesos permite obtener productos de buena calidad (iso, 1993). Esto no siempre es cierto, pues las normas no garantizan que se esté cumpliendo con los indicadores o especificaciones absolutos de calidad.

A fin de controlar y evaluar la eficacia de una organización para reducir al mínimo los defectos de calidad pueden crearse estructuras de cálculo de costos de calidad. La técnica de determinación de costos en función de la actividad puede ser una metodología adecuada que facilitará la creación de sistemas de cálculo de costos de calidad a nivel de la actividad (proceso). Los costos de calidad pueden dividirse en aquellos derivados de las actividades de prevención y garantía de la calidad y los vinculados con fallas internas y externas. Por lo tanto, para optimizar el gasto en calidad es preciso equilibrar los costos de prevención y de evaluación (costos de calidad) con los beneficios derivados de la reducción de las fallas de calidad (costos no relacionados con la calidad) (Van de Broek, 1991).

Se dice que el gasto en crear y mantener los sistemas de gestión de calidad (clasificados como costos 
de prevención y evaluación) contribuye a reducir los costos no relacionados con la calidad. Por ejemplo, se estima que para las empresas medianas y grandes los costos de implementación y certificación de sistemas de calidad con arreglo a las normas iso 9000 oscilan entre $0.5 \%$ y $1.5 \%$ de sus ventas. Asimismo, se ha estimado que las economías tangibles que se logran en los costos de calidad, expresadas como porcentaje de las ventas, son varias veces mayores (Schuurman, 1997b). Una de las ventajas de establecer estructuras de cálculo de costos de calidad es que pueden producir resultados tangibles, útiles para justificar y facilitar la adopción de (nuevas) técnicas de gestión de calidad. Tal vez otra ventaja de los costos de calidad consistiría en que permiten cuantificar los resultados de la gestión de calidad. Tales ventajas pueden contribuir significativamente a mejorar el desempeño, la conformidad con las especificaciones, la durabilidad y la utilidad de los productos, lo que a su vez puede resultar en un aumento de la demanda y de la participación de la empresa en el mercado. Puede decirse que estas mejoras aumentan la rentabilidad, pero es difícil atribuirlas exclusivamente a la implementación de la gestión de calidad (Winchell, 1987; Spitzer, 1993).

En cuanto a los costos relacionados con la calidad, en la literatura respectiva se citan las conclusiones siguientes:

i) Los costos de calidad equivalen a un porcentaje importante de las ventas. En un estudio realizado en los Países Bajos se concluye que los costos de calidad difieren de un sector industrial a otro, pero en promedio ascienden a un $10 \%$ de las ventas. En otro estudio que abarcó 54 empresas en Francia se informa que los costos de calidad oscilan entre un $5 \%$ y un $23 \%$ de las ventas (Van de Broek, 1991). La Organización Internacional de Normalización (iso) estima que los costos derivados de los defectos de calidad oscilan entre 15 y $25 \%$ de las ventas en los países desarrollados y que probablemente son aún mayores en los países en desarrollo (ISO/UNCTAD/GATT, 1993).

ii) Entre 60 y $70 \%$ de los defectos de calidad que se detectan en el taller pueden atribuirse directa o indirectamente a errores cometidos en otras áreas, como las de diseño, estudios técnicos, adquisiciones, producción, embalaje, despacho y transporte, pese a que la mayoría de las actividades tradicionales de garantía de calidad (inspección) se centran en el taller (Nakamura, 1992).

iii) Las actividades tendientes a mejorar la calidad (conforme a los principios de la gestión total de la calidad, o a través de medidas de prevención o evaluación) pueden reducir notoriamente los costos de calidad. En los Países Bajos las empresas han logrado economías que promedian el 3\% del volumen total de los negocios, de 10 a 7\% (Van de Broek, 1991). Se estima que una organización puede reducir sus costos de calidad de $23 \%$ a cerca de $6 \%$ en un plazo de 4 a 5 años, es decir, el tiempo necesario para implantar un sistema de gestión total de la calidad (TUV Reinland Chile, (1995). ${ }^{9}$

La mayoría de los costos de calidad en la fase de implantación de un sistema de este tipo están vinculados con las actividades de prevención y evaluación y compensan ampliamente los costos derivados de los defectos de calidad (desechos, reprocesamiento y garantías).

\section{Plazos de entrega razonables}

Además de suministrar al cliente productos y servicios en cantidad y calidad adecuadas y a un precio aceptable, también es preciso garantizar plazos de entrega breves y confiables, pues este último factor puede ser fundamental para que la empresa mejore su competitividad. En particular, para las empresas que utilizan técnicas de gestión de calidad operacionales en el proceso de producción, como el sistema de fabricación justo a tiempo, el plazo de entrega de insumos físicos es importante; con frecuencia tal plazo está vinculado con la optimización del proceso logístico de la empresa, que puede incidir no sólo en el tiempo hábil del área de distribución sino en el de otras áreas funcionales como la producción y el desarrollo de nuevos productos y procesos (véase la subsección 4). La selección de una estructura organizacional adecuada o la forma en que se agrupan las funciones (procesos) es importante para optimizar los plazos de entrega. Por ejemplo, la estructura organizacional puede clasificarse por tipo de actividad (función), producto o servicio y/o ubicación geográfica.

A menudo se utilizan técnicas y métodos estadísticos de gestión de calidad para controlar y mejorar los procesos logísticos. Otra técnica supone reubicar dentro del sistema de producción el punto de suministro del pedido del cliente, que es el último punto de suministro de los materiales importantes en que puede

\footnotetext{
9 Para mayor información sobre las fases de implantación de un sistema de gestión total de la calidad, véase la sección IV.
} 
cumplirse con dicho pedido. El traslado de ese punto de suministro a una etapa más avanzada del sistema de producción (más cercana al producto final) permite lograr plazos de entrega más breves y confiables (Pandora, 1989). Por ejemplo, si se asigna el punto de suministro del pedido del cliente a la etapa de inventario de los componentes principales, el producto final puede armarse con dichos componentes cuando se recibe el pedido del cliente. En ese caso, el tiempo de armado será el componente principal del plazo de entrega. La noción de competencia basada en los plazos de entrega es un concepto integral de gestión que comprende el manejo de los factores cronológicos dentro de la organización (Wildschut, 1993).

\section{Flexibilidad: diversidad o singularidad del pro- ducto}

La flexibilidad es la capacidad de encarar la creciente diferenciación y volatilidad de los mercados. En el presente análisis debe entenderse por flexibilidad la capacidad de producir oportunamente la variedad y cantidad adecuadas de productos según la demanda del mercado. La creación de una estructura flexible incidirá en la organización, estructuración y planificación del proceso de producción, en el que la eficiencia, la calidad y los plazos de entrega serán parámetros importantes. Evidentemente, no se excluyen de este análisis los productos nuevos, de modo que los conceptos de flexibilidad e innovación pueden superponerse. Por lo general, la flexibilidad del proceso de producción para satisfacer adecuadamente la demanda del mercado exige períodos de ajuste más breves, variaciones en la cantidad de insumos y estrategias centradas en los costos, mientras que la flexibilidad en materia de innovaciones normalmente exige períodos de ajuste más prolongados, recursos humanos, mejoras en la productividad $y$ la elaboración de estrategias centradas en el desarrollo de productos y procesos nuevos (Reinecke, 1996).

El manejo de la flexibilidad es importante pues los consumidores exigen gran cantidad de familias y variedades de productos. Además, la demanda de los consumidores fluctúa en el tiempo. Por ese motivo, es preciso organizar la producción por lotes y tener en cuenta que el tiempo necesario para ajustar las instalaciones con el fin de producir lotes nuevos (tiempo no productivo) puede ser considerable. Una forma de encarar las fluctuaciones de la demanda es tener inventarios de productos terminados. Sin embargo, esta solución puede resultar excesivamente cara y arriesga- da, habida cuenta de la gran variedad de productos y los rápidos cambios en la demanda del mercado. Como los productores deben enviar sus productos a los clientes en un plazo determinado, el control del tiempo hábil en el proceso de producción es esencial. Ello exige que la empresa se maneje con flexibilidad en varios aspectos:

i) Flexibilidad en los productos: capacidad de efectuar cambios fácilmente para producir distintas variedades de productos;

ii) Flexibilidad en materia de maquinaria: capacidad de fabricar los diversos componentes de una misma familia de productos;

iii) Flexibilidad en los procesos: capacidad de producir una familia de productos de varias maneras, utilizando, por ejemplo, distintos materiales;

iv) Flexibilidad volumétrica: la capacidad de adaptarse a las variaciones del rendimiento asociadas al volumen de producción;

v) Flexibilidad funcional: capacidad del personal para realizar distintas tareas y así asumir las flexibilidades antes mencionadas;

vi) Flexibilidad numérica: en la cantidad de empleados que integran la plantilla, las horas extraordinarias, los horarios y la subcontratación;

vii) Flexibilidad en los incentivos: en materia de salarios y de regímenes de promoción y bonificación, a fin de premiar al personal por sus esfuerzos individuales o colectivos.

Para flexibilizar los procesos de producción hay varias técnicas de gestión que pueden aplicarse, entre ellas el sistema de gestión justo a tiempo, el kanban, $y$ el diseño celular de fábricas. El sistema justo a tiempo entraña organizar la producción de modo tal que se pueda producir el volumen necesario, en el momento oportuno y con la calidad adecuada. Con frecuencia se piensa en recurrir a tal sistema en función de las relaciones con los proveedores; sin embargo es posible que la implantación de un sistema justo a tiempo interno sea un requisito previo a la implantación de uno externo. En el sistema interno es preciso reducir el volumen de los lotes, y la eficiencia de la producción es mayor cuando los flujos de materiales son sencillos y sin complicaciones; además, se debe contar con mano de obra poliespecializada y capaz de realizar distintas tareas. En el sistema externo será necesario contar con subcontratistas de varios niveles que puedan suministrar partidas pequeñas de insumos y establecer sistemas de coordinación con los organismos estatales encargados de la ejecución de políticas económicas e industriales de largo plazo (Japón). 
El kanban es una forma de control de inventarios y producción en la que se utilizan procedimientos manuales y administrativos sencillos. En este sistema, la demanda de la etapa siguiente de la producción cumple una función de arrastre y funciona mejor en situaciones de demanda estable y cantidad de productos limitada. En el diseño celular se crean pequeñas fábricas que en su conjunto abarcan varios procesos c instalaciones capaces de producir una familia completa de productos (en este tipo de diseño se aplican con frecuencia los sistemas kanban y justo a tiempo). Evidentemente, este tipo de técnicas operacionales exigen mayor responsabilidad de los operadores y para aplicarlas con eficacia es fundamental contar con mano de obra bien calificada y capacitada (Vispo, 1994).

\section{Innovación: nuevos productos}

A lo largo de los últimos decenios las empresas que operan en los mercados mundiales han competido sucesivamente mediante los precios, la calidad, los plazos de entrega y la flexibilidad. A la luz de la ampliación y apertura de los mercados y el aumento del poder adquisitivo de los consumidores es probable que la demanda de éstos en los mercados mundiales se vuelque a productos de mayor calidad y singularidad y que incorporen las innovaciones más recientes. Además, mediante las tecnologías avanzadas y la automatización, las empresas se especializarán en submercados, lo que traerá aparejados un envejecimiento y depreciación más acelerados de los productos y de la maquinaria. En consecuencia, es dable esperar que en el futuro inmediato el factor adicional determinante de la competencia en los mercados mundiales sea la innovación.

Como se ha dicho, los mercados están sometidos a cambios acelerados que reducen la vida útil de los productos. Los productores deberán estar en condiciones de colocar las innovaciones en el mercado reduciendo al mínimo los tiempos necesarios para diseñar, desarrollar y lanzar nuevos productos y procesos. Por ejemplo, un indicador de la medida en que se han producido innovaciones puede ser la relación entre el número de productos nuevos que han ingresado al mercado en los últimos dos a cuatro años y el número de productos totales que se comercializan (Kaplinski, 1995). El concepto actual del diseño se acerca cada vez más al de desarrollo de productos. No sólo es necesario cumplir con las características técnicas y funcionales del producto, sino que es preciso asegurar su comercialización. Los criterios enunciados están vinculados íntimamente con las aspiraciones del consumidor e incluyen aspectos como la imagen, el reconocimiento y la forma. Una vez que se define un nuevo concepto de producto, prácticamente el $80 \%$ de las decisiones adoptadas tienen que ver con el costo de producción y el uso. Además, las fases de investigación y desarrollo y de diseño determinan aproximadamente el $70 \%$ de los costos de calidad en que se incurre en las etapas posteriores (Maas, 1992).

El desarrollo acelerado de nuevos procesos y productos depende en gran medida de la capacidad de la empresa para aprovechar sus conocimientos, tanto en lo interno como en su entorno más directo. Esto significa que todos pueden contribuir al mejoramiento de sus actividades, inclusive los consumidores, los trabajadores, los proveedores, el personal y los directivos. En consecuencia, las posibilidades de innovación dependen de una participación dinámica de las distintas áreas funcionales y pueden surgir si se logra un equilibrio adecuado entre creatividad y control. Por un lado, los procedimientos burocráticos rígidos inhiben la creatividad y, por el otro, la falta de disciplina puede provocar el caos y la falta de profesionalismo. A menudo, la innovación (investigación y desarrollo) es un proceso a largo plazo que puede significar inversiones importantes y traer aparejados cambios estructurales fundamentales en la organización. Lo dicho subraya la importancia de la planificación estratégica de las innovaciones en materia de gestión de la calidad.

En general, la formulación de proyectos y la gestión de la calidad son instrumentos aptos para controlar los procesos de innovación y cambio. El despliegue de la función de calidad es un método de planificación sistemática que integra la satisfacción del cliente al desarrollo de productos y procesos. Taguchi ha desarrollado una técnica similar, en la que se hace hincapié en el control de calidad en la fase de diseño. Ambas son técnicas de planificación que apuntan a individualizar los aspectos fundamentales del diseño, reducir los costos de fabricación y los tiempos muertos y lograr productos de mejor calidad a menor costo. Con frecuencia, la responsabilidad de aplicar estos métodos recae en los equipos encargados del producto, integrados por distintos sectores funcionales. Asimismo, los círculos de control de la calidad (grupos de trabajo en los que participan los distintos sectores funcionales y jerárquicos) tratan de identificar oportunidades de innovación en su aspecto más general y no se limitan necesariamente al proceso de diseño. 


\section{IV}

\section{Aplicación de la gestión total de calidad}

A fin de aplicar fa gestión total de calidad, las empresas deben formular y aplicar estrategias relacionadas con la calidad y estar en condiciones de adaptarlas en cualquier momento en respuesta a cambios de las condiciones del mercado circundante, los clientes y los proveedores. La planificación estratégica de la calidad tiene por objeto orientar todas las actividades relacionadas con la puesta en el mercado del producto o servicio, desde la etapa de investigación y desarrollo, pasando por la producción y la comercialización, hasta los servicios de posventa, tanto a nivel de la empresa como entre empresas (Kaplinski, 1995). Como se ha explicado en la sección anterior, los conceptos de satisfacción del cliente y de mejoramiento continuo constituyen la base del desempeño competitivo, y a su vez pueden desglosarse en los siguientes:

i) La definición de las competencias básicas y la maximización de la productividad del capital y el trabajo (eficiencia);

ii) La eliminación, hasta donde sea posible, de los defectos de calidad en las actividades de organización, los servicios y los productos (calidad);

iii) La optimización del tiempo hábil total (plazo de entrega);

iv) La organización y el control de los insumos y productos a fin de responder a una demanda del mercado diversa y fluctuante (flexibilidad), y

v) La organización y el control del diseño y desarrollo de productos, a fin de responder oportunamente o anticiparse a los cambios en las condiciones del mercado (innovación).

En el recuadro 1 se expone una posible estrategia empresarial para implementar diversas técnicas de gestión de calidad. En esencia, la implementación de la gestión total de la calidad significa aplicar en forma dinámica los conceptos de satisfacción del cliente y de mejoramiento continuo con la máxima eficiencia y eficacia. En el recuadro se observa que la combinación de dos estrategias reactivas implica poca eficiencia y poca eficacia (es decir, lo innecesario se hace mal). Una organización muy eficiente pero poco eficaz realiza correctamente actividades innecesarias, en tanto que una organización eficaz pero poco eficiente hace mal lo necesario. Mediante la combinación de dos estrategias dinámicas, la empresa cumple con criterios concretos de calidad y competencia tanto en lo inter- no como en lo externo (es decir, hace bien lo necesario).

Durante el proceso de aplicación gradual de la gestión total de la calidad, las organizaciones irán aplicando sucesivamente las condiciones enumeradas en los cuadrantes segundo, tercero y cuarto del recuadro. Esto dependerá de sus recursos internos y de las condiciones que imponga la competencia en los mercados en que operan. La internalización del concepto de satisfacción del cliente a menudo entraña la reorganización de varios departamentos en algunos procesos claves del sistema de producción, lo que a su vez exige mejorar la cooperación entre las diversas funciones. Una vez que esto se ha logrado, los departamentos funcionales procuran mejorar su rendimiento comercial y la eficiencia en función de los costos mediante instrumentos de gestión que permitan un mejoramiento continuo de sus actividades. El impulso necesario para mantener el proceso de calidad total se logra con el desarrollo de una mentalidad adecuada en la organización. Lo dicho subraya la importancia que reviste la capacidad de liderazgo de los directivos para promover los conceptos de la calidad total y el que dicho liderazgo se ejerza mediante una estrategia de calidad (Technovation, 1994).

Conforme a una encuesta realizada en 700 empresas de los Países Bajos (Dutch Institute for Quality, 1996), éstas pueden clasificarse según la fase en que se hallen en la aplicación de los principios de gestión de la calidad. Esas fases dependerán de la orientación y el alcance que se dé a este proceso:

Fase 0: Casi no se aplican técnicas de gestión de calidad.

Fase 1: Se aplican a nivel de producto (inspección de la calidad del producto).

Fase 2: Se aplican a nivel de procesos (gestión de calidad en los procesos de las diversas áreas funcionales).

Fase 3: Se aplican a nivel del sistema de gestión de calidad, (por ejemplo, iso 9000).

Fase 4: Se aplican en toda la cadena de producción (gestión de la calidad en relación con los clientes y proveedores).

Fase 5: Hay gestión total de la calidad (integración y aplicación simultánea de las fases anteriores de la gestión de calidad). 


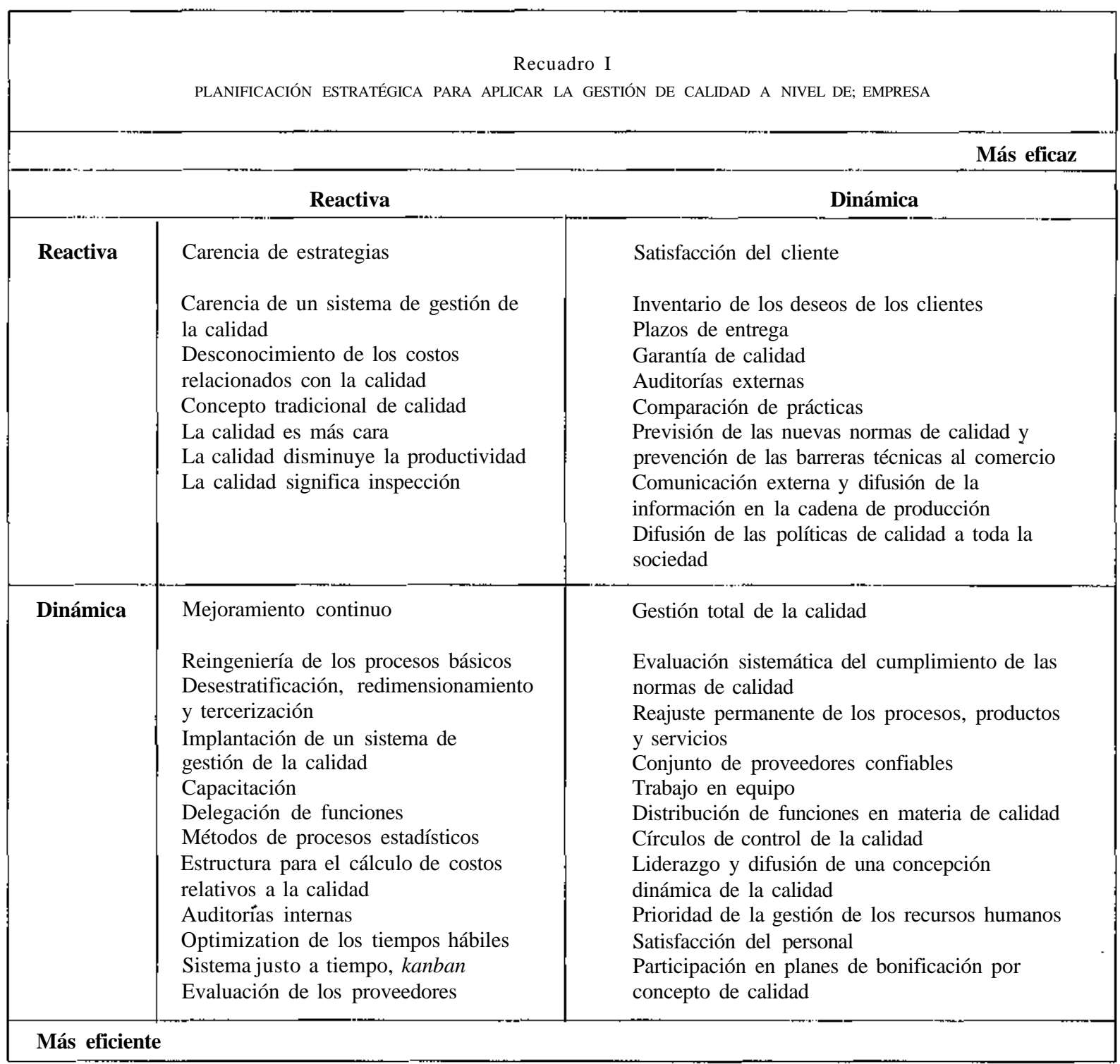

\section{V}

\section{Importancia de la gestión de la calidad y obstáculos para aplicarla}

Según la Comisión Europea (1995), la conciencia de la importancia que reviste la gestión de la calidad en el Japón y los Estados Unidos es excelente y buena, respectivamente. Confirman esta calificación las principales conclusiones de una encuesta (American Quality Foundation, 1991) sobre las prácticas de ges- tión de la calidad que aplican más de 500 empresas de Alemania, los Estados Unidos y el Japón. Según el informe;

i) Más de $50 \%$ de las empresas encuestadas evalúan la incidencia del cumplimiento de las normas de calidad sobre los resultados comerciales por lo menos una vez al mes; 
ii) $40 \%$ de las empresas asignan una prioridad importante en su planificación estratégica a la satisfacción del cliente;

iii) $30 \%$ de las empresas norteamericanas y japonesas conceden suma importancia al análisis de las prácticas de la competencia (comparación de prácticas);

iv) $90 \%$ de las empresas japonesas y $25 \%$ de las estadounidenses practican permanentemente la reingeniería de los procesos de producción o de servicios; y

v) Todas las empresas consideran que los equipos para elevar la calidad integrados por los distintos sectores funcionales son el mejor instrumento para aumentar la participación del personal.

En la mayoría de los países europeos se considera que no hay suficiente conciencia de la importancia de la gestión de calidad. En una encuesta realizada por el Dutch Institute for Quality (1996) se señala que $45 \%$ de las 700 empresas participantes centran su estrategia de calidad en los procesos primarios y los procesos secundarios conexos. Muy pocas empresas se preocupan por los objetivos sociales o tratan de mejorar los procesos mediante la comunicación con los clientes y proveedores. Según la encuesta, $70 \%$ de las empresas están situadas en las fases 2 y 3 de la aplicación de los principios de gestión de la calidad (enumeradas en la sección IV). Sólo $2 \%$ de las empresas encuestadas consideran que han alcanzado la fase de gestión total de la calidad, mientras que el $13 \%$ ha alcanzado la fase 4. El grupo restante (fase 0) representa el $15 \%$.

En la práctica, no es fácil incorporar las cuestiones vinculadas con la calidad a la estrategia de las empresas, debido principalmente a las dificultades que presenta la definición de objetivos tangibles a ese respecto. Asimismo, la implementación de innovaciones organizativas (como la gestión total de calidad) se realiza en forma menos sistemática que la de las innovaciones tecnológicas. Esto se debe a que las técnicas de gestión de calidad entrañan cambios en la forma de pensar y relacionarse del personal; afectan a la gran mayoría de los miembros de la organización; modifican la estructura de responsabilidades; exigen gran dedicación a la dirección de la empresa, y dan lugar a diversas interpretaciones. En consecuencia, la aplicación de tales técnicas supone incorporar innovaciones organizativas complejas y globales, a menudo en etapas sucesivas. Se trata de un proceso de aprendizaje gradual y acumulativo. Así, puede observarse que la mayoría de las empresas que han incorporado la ges- tión de calidad lo han hecho utilizando un método de ensayo y error que evoluciona mediante una acumulación continua de capacidades, que comienza en las áreas especializadas y que más adelante pasará a integrar un marco estratégico y de relaciones externas sólido (Fleury, 1995).

Teniendo en cuenta la clasificación del World Competitiveness Report sobre la aplicación de la gestión total de la calidad y la reducida cantidad de empresas ( $1 \%$ del total) certificadas con arreglo a las normas iso $9000^{10}$ (cuadro 1), puede concluirse que la aplicación de técnicas de gestión total de la calidad y la percepción de los problemas de la calidad en América Latina son limitadas u ocasionales. A fin de comprender algunos de los factores determinantes de esta situación, se analizarán en seguida los obstáculos para aplicar la gestión de la calidad en la región." El interrogante principal es el de dilucidar si llegar al uso generalizado de las prácticas de gestión de la calidad es sólo cuestión de tiempo, puesto que el aprendizaje es un proceso secuencial, o si hay tal vez factores concretos que dificultan la aplicación sistemática de técnicas de gestión de la calidad.

\section{Problemas vinculados al comercio y el merca- do}

Cuando a fines de los años ochenta la mayoría de los gobiernos de América Latina comenzaron a abandonar las prácticas de sustitución de las importaciones, hubo un aumento del comercio internacional y de la inversión extranjera directa. La presión competitiva de los mercados internacionales ha generado la necesidad de innovaciones tecnológicas y de organización. Una parte importante del intercambio comercial se produce entre los países de la región. Pese a la existencia de varios acuerdos regionales de libre comercio, la demanda de sistemas estructurados de gestión de la calidad se ha limitado a algunos países y sectores industriales. En consecuencia, las prácticas de gestión y garantía de la calidad que se observan en el comercio intrarregional se limitan a la inspección de los productos y (aún) no se han aplicado aquéllas más vinculadas a los procesos, del tipo establecido en las normas iso 9000 .

\footnotetext{
10 Se supone que el número de certificaciones otorgadas conforme a las normas iso 9000 en un país determinado es un indicador de la tendencia a adoptar técnicas de gestión de la calidad (Schuurman, 1997a).

" Salvo que se indique lo contrario, el autor agradece a Humphrey (1993 y 1995), Kaplinski (1993 y 1995) y Fleury (1993 y 1995) por la información presentada.
} 
CUADRO !

Algunos regímenes y países: Empresas que cuentan con sistemas de calidad certificados conforme a las normas $\mathbf{1 S O} 9000$

(Número de empresas y porcentajes)

\begin{tabular}{|c|c|c|c|c|c|}
\hline Región o país & Enero de 1993 & Junio de 1994 & Marzo de 1995 & Diciembre de 1995 & Porcentajes \\
\hline Reino Unido & 18577 & 36832 & 44107 & 52591 & 41 \\
\hline Europa continental & 4515 & 18577 & 27810 & 40019 & 31 \\
\hline Alemania & 790 & 3470 & 5875 & 10236 & \\
\hline Francia & 1049 & 3359 & 4279 & 5535 & \\
\hline Países Bajos & 716 & 2718 & 4198 & 5284 & \\
\hline Italia & 188 & 2008 & 3146 & 4814 & \\
\hline España & 43 & 586 & 942 & I 492 & \\
\hline América del None & 1185 & 4830 & 7244 & 10159 & 8 \\
\hline Estados Unidos & 893 & 3960 & 5954 & 8762 & \\
\hline Pacífico & 1862 & $462 \mathrm{~S}$ & 6479 & 10526 & 8 \\
\hline Australia & 1668 & 3710 & 5299 & 8834 & \\
\hline Asia & 692 & 3421 & 6568 & 10278 & 8 \\
\hline Japón & 165 & 1060 & 1827 & 3762 & \\
\hline \multicolumn{6}{|l|}{ Países de } \\
\hline industrialización reciente ${ }^{3}$ & 382 & 1561 & 3004 & 3892 & \\
\hline India & 8 & 328 & 585 & 1023 & \\
\hline China & 10 & 150 & 285 & 507 & \\
\hline Asia sudoriental ${ }^{\mathrm{b}}$ & 4 & 59 & 229 & 370 & \\
\hline Africa y Medio Oriente ${ }^{I,}$ & 954 & 1705 & 2286 & 2340 & 2 \\
\hline Sudáfrica & 824 & 1161 & 1369 & 1454 & \\
\hline Israel & 110 & 279 & 497 & 526 & \\
\hline \multicolumn{6}{|l|}{ Arabia Saudita $y$ los } \\
\hline Emiratos Árabes Unidos & 7 & 65 & 108 & 202 & \\
\hline América Latina & 39 & 533 & 873 & 1440 & 1 \\
\hline Brasil & 19 & 348 & 548 & 932 & \\
\hline México & 16 & 85 & 145 & 215 & \\
\hline Total $^{\prime \prime}$ & $27 * 24$ & 70526 & 95367 & 127389 & \\
\hline
\end{tabular}

Fuente: ISO 9000 News, 1996.

a El porcentaje de certificados emitidos hasta diciembre de 1995 en la provincia china de Taiwán fue de 35\%, en Singapur de 30\%, en Hong Kong de $19 \%$ y en la República de Corea de $16 \%$,

${ }^{\mathrm{b}}$ El porcentaje de certificados emitidas hasta diciembre de 1995 fue de 39\% en Tailandia, 34\% en Indonesia y 27\% en Filipinas.

c La mayor parte de los certificados se emitieron en Sudáfrica (62\%), Israel (23\%), Arabia Saudita (4\%) y los Emiratos Árabes Unidos (4\%).

d Se estima que en el período 1998-1999 se habrán emitido aproximadamente 225000 certificados conforme a las normas iso 9000.

En los mercados locales, la mayor parte de los consumidores tienen poco poder adquisitivo y adoptan sus decisiones de compra por precio más que por calidad. En aquellos mercados locales en que la demanda de bienes de consumo excede la oferta, se puede vender cualquier cosa. Como los niveles de instrucción son bajos, los conocimientos de los consumidores sobre la calidad y sus implicaciones son limitados. Además, la falta de competencia internacional, resultante de las medidas proteccionistas aplicadas en el pasado, ha obstaculizado el desarrollo de una conciencia nacional sobre la calidad, aunque los consumidores e industriales suelen admirar la de los bienes importados.
En la actualidad, la existencia de mercados más abiertos a las importaciones obliga a los productores locales a competir con ellos y, en consecuencia, a prestar más atención a la calidad (ISO/UNCTAD/GATT, 1993).

\section{Acceso de las empresas a los recursos}

En términos generales, la falta de recursos adecuados y de una conciencia de la calidad a nivel empresarial son los factores que más retrasan la aplicación generalizada de las técnicas de gestión de calidad en América Latina. Mientras que las empresas transnacionales, los grupos económicos nacionales y las empresas de 
propiedad del Estado pueden obtener los recursos necesarios, no hay duda de que para las empresas pequeñas y medianas (PYME) acceder a estos recursos es mucho más complicado, especialmente en períodos de inestabilidad macroeconómica. Las situaciones de estabilidad favorecen la definición de estrategias empresariales competitivas a largo plazo, las corrientes de inversión extranjera y las inversiones en modernización de equipo. Por el contrario, la inestabilidad macroeconómica y las tasas de inflación elevadas restringen la planificación a mediano y largo plazo en el sector privado y, con frecuencia, elevan las lasas de interés. Las reducciones consiguientes de las actividades de capacitación y de la fuerza de trabajo minan la motivación de los empleados para participar en la implementación de la gestión de calidad, en el caso de que la empresa decida aplicarla.

Por lo general, las presiones que ejerce el mercado local sobre las PYME proveedoras para que apliquen técnicas de gestión de calidad se transmiten del cliente al proveedor a través de la cadena de producción. Por ejemplo, la empresa SIDERAR (filial de un grupo económico nacional importante de Argentina, dedicada a la producción de metales básicos) evalúa a sus proveedores en función de su estabilidad financiera y nivel de modernización tecnológica $(50 \%)$ y de la utilización de técnicas de gestión de la calidad (50\%). En relación a este último aspecto, es posible que SIDERAR exija la certificación conforme a las normas iso 9001 o 9002, según el tipo de proveedor de que se trate y la importancia de su contribución a las actividades de la empresa (Schuurman, 1997b). Sin embargo, para muchas PYME el objetivo es producir determinados productos y no satisfacer las necesidades del mercado, por lo cual su interés por los clientes o la calidad del servicio es secundario. No es frecuente que en este tipo de empresas se asigne mayor importancia a la documentación relativa a los sistemas de calidad que, por lo general, no está muy sistematizada. De lo anterior se puede inferir que la información sobre la función de producción está muy poco estructurada. En consecuencia, el sector de las PYME podría beneficiarse sobremanera con la aplicación de sistemas de calidad conforme a las normas iso 9000, ya que éstas permiten una definición más adecuada de las rutinas operacionales (Schuurman, 1997b, y Ramos, 1995).

Un estudio sobre las PYME de Brasil indica que muchas empresas o rubros de los sectores tradicionales carecen de la capacidad interna necesaria para adaptarse a las exigencias que les plantean las empresas clientes en materia de garantía de calidad. En otro estudio realizado en el mismo país por el Servicio Brasileño de Apoyo a las Microempresas (SEBRAE) en 1994 y que abarcó 35 empresas pequeñas, 38 medianas y 37 grandes, certificadas o con certificación en trámite conforme a las normas iso 9000 , se señaló que $85 \%$ de las empresas pequeñas, $75 \%$ de las medianas y $55 \%$ de las grandes tenían dificultades para establecer sistemas de calidad conformes a esas normas. Además, $80 \%$ de las empresas pequeñas, $45 \%$ de las medianas y $25 \%$ de las grandes necesitaban recurrir a servicios de consultoría externa (Asociación Brasileña de Normas Técnicas, 1996). Asimismo, en una encuesta realizada en Brasil (INMETRO/MICT, 1996), que abarcó 592 empresas certificadas con arreglo a las normas iso 9000, se informó que aproximadamente un $55 \%$ de ellas recurría a servicios de consultoría externa, mientras que en las empresas pequeñas (de menos de 100 empleados) la proporción ascendía a $70 \%$.

\section{Prácticas de gestión tradicionales}

En América Latina la poca importancia que se da a la calidad puede atribuirse al predominio de prácticas de gestión tradicionales, que generan resistencias al cambio en el personal, falta de compromiso de la plana mayor empresarial y escaso desarrollo de los recursos humanos.

La introducción de técnicas de gestión de calidad obliga a reorganizar la asignación de responsabilidades y las estructuras de poder. Las prácticas laborales tradicionales (métodos autoritarios, división minuciosa de las tareas) dificultan la creación de un tipo de organización que cuente con estructuras más horizontales, en la que los empleadores concedan a los empleados más confianza y responsabilidades. Si bien es posible mejorar la producción mediante la aplicación de innovaciones organizativas, la resistencia de los cuadros superiores e intermedios de los diversos departamentos puede convertirse en un obstáculo importante para poner en vigor oportunamente la gestión de calidad. Esto puede llevar a acciones poco coherentes derivadas de las visiones parciales de los departamentos especializados. En consecuencia, es fundamental que los cuadros superiores de la empresa apoyen con firmeza la implantación del concepto de calidad. A este respecto, cabe señalar que en la mayoría de las empresas que no han podido aplicar la gestión de calidad se ha tropezado con la falta de compromiso de los cuadros directivos para encabezar esta tarea, o se le ha prestado poca atención a ella, o no se han asignado los recursos necesarios. Es decir, se ha dado escasa prio- 
ridad a la gestión de la calidad y se la ha considerado una actividad ocasional.

Es importante que los trabajadores comprendan sus nuevas obligaciones y estén capacitados para manejar las nuevas técnicas y tecnologías de gestión de la calidad, para lo cual las empresas deberán iniciar programas de capacitación y de desarrollo de recursos humanos. Un análisis de las prácticas utilizadas en México en materia de empleo indica que la formación de personal calificado se resuelve con frecuencia contratando empleados jóvenes y motivados a los que se imparte capacitación intensiva en el empleo (Shaiken, 1994). Sin embargo, algunos estudios realizados en Brasil señalan que si bien los esfuerzos dirigidos a mejorar la calidad y la productividad han permitido aumentar la eficacia y perfeccionar las prácticas de gestión, en muchos casos no han dado como resultado una mayor participación de la fuerza de trabajo, debido entre otras cosas a la escasa capacitación de los trabajadores vinculados directamente con la producción. Por otra parte, para los empleadores los gastos de capacitación son elevados pues el nivel de instrucción de los trabajadores es bajo y la tasa de rotación del personal en los mercados de trabajo de las PYME es alta.

\section{Análisis a nivel macroeconómico}

Es posible que la difusión de las técnicas de gestión de la calidad en América Latina se haya visto obstaculizada por varios factores a nivel macro. A continuación se analizarán sucintamente algunos de ellos, como la falta de suficiente capacidad y apoyo institucionales, la carencia de una red adecuada de proveedores o subcontralistas, los problemas laborales y los aspectos culturales.

En Japón, Gran Bretaña y Suecia, por ejemplo, se ha comprobado que para difundir las técnicas de gestión de la calidad es preciso contar con algún tipo de red institucional. En estos países, las asociaciones de industriales y empleadores, los institutos de investigación y los organismos de gobierno, tanto a nivel nacional como a nivel intermedio, han aportado los recursos financieros, el apoyo tecnológico y la información necesarios para alentar la difusión de tales técnicas. El grado de apoyo institucional varía considerablemente entre los diversos países de América Latina (y también entre las distintas regiones de un mismo país). En muchos casos, para establecer una red institucional es preciso contar con el apoyo de los gobiernos.
Para aplicar las técnicas de gestión de la calidad es preciso que los proveedores modifiquen sus prácticas tradicionales y sean capaces de cumplir con entregas de sus productos en lotes pequeños de calidad garantizada, ya que cualquier defecto de calidad en las existencias reguladoras provocará demoras. Es posible que los subcontratistas externos y las empresas de servicios públicos no puedan cumplir con las exigencias que plantean los nuevos métodos de producción de la empresa cliente. Por ejemplo, en el sector de fabricación de autopartes de Brasil hay empresas proveedoras que al parecer han podido adaptarse a un nivel técnicamente avanzado de gestión de la calidad. En muchos casos se trata de filiales de empresas internacionales que apoyan enérgicamente estos cambios. Con frecuencia, las empresas clientes prestan asistencia a los programas de implementación de la calidad, haciendo hincapié en los aspectos técnicos y operacionales. Tales empresas han manifestado que no han podido aplicar las prácticas de gestión de la calidad a nivel operacional (como los sistemas justo a tiempo) en forma total, porque los grandes proveedores de materiales (como el acero) y de servicios públicos (como la electricidad) no podían garantizar la cantidad, calidad y confiabilidad del suministro. Por lo demás, si se desea promover la creación de una red de proveedores dinámica y flexible y asegurar su funcionamiento, es preciso contar con una infraestructura física adecuada.

Las condiciones del mercado de trabajo desempeñan un papel importante en la adopción de la gestión de la calidad, ya que ésta exige trabajadores multifuncionales, flexibilidad y espíritu innovador en la planta y asignación de mayores responsabilidades y tareas relacionadas con la producción propiamente dicha. En América Latina, los empleadores han sido reacios a invertir en programas de capacitación para los trabajadores vinculados directamente a la producción y a mejorar sus salarios y perspectivas de ascenso, pese a que ambas cosas son esenciales para asegurarse la adhesión de estos trabajadores. Habida cuenta de la importancia que revisten las cuestiones laborales en la gestión de la calidad, parece haber espacio para aumentar la participación activa de las organizaciones laborales.

\section{Aspectos culturales}

En su descripción del sistema de comportamiento humano, Brache (1988) afirma que el individuo recibe estímulos (insumo), genera respuestas (producto) y 
luego adapta su conducta a las consecuencias o a la retroalimentación recibida. La calidad del desempeño de un individuo se ve afectada por cuatro factores. En primer lugar, por los estímulos que recibe; estos estímulos comprenden la claridad de las expectativas sobre su desempeño, la racionalidad de los procedimientos laborales, un nivel de conocimientos y pericia suficientes y la claridad de las señales (incentivos) que gatillan su desempeño. En segundo lugar, por las percepciones positivas o negativas que resultan de realizar tareas deseadas o no deseadas. En tercer lugar, por la calidad de la retroalimentación que le llega (es decir, el tipo de información que se le suministra, la oportunidad y la frecuencia con que la recibe, y la forma en que se le transmite, etc). Y por último, por su capacidad física, mental y emocional para cumplir con sus funciones.

En consecuencia, para crear una "cultura de la calidad" en una organización se necesitan claras estrategias y procedimientos de trabajo, conciencia de la importancia de la calidad, y también comunicación. En América Latina la prioridad otorgada a la estandarización en materia de calidad y a la capacitación dentro de la empresa ha sido baja y, en general, no ha habido suficiente conciencia de la importancia de la calidad. Las técnicas de gestión tradicionales han des- embocado en un sistema de comunicación de mando y control, estructurado sobre bases jerárquicas y con mecanismos de recompensas e incentivos a menudo vedados a gran parte de la fuerza de trabajo. Sin embargo, sería difícil demostrar que estos aspectos son inherentes a las culturas latinoamericanas (o que no pueden modificarse). Por lo general, se considera que los factores culturales que imperan en las sociedades o regiones no impiden la aplicación de las técnicas de gestión de la calidad, porque i) casi todas las prácticas de gestión total de la calidad se han podido transferir sin inconvenientes entre diferentes países y culturas, y ii) se ha utilizado una gama de incentivos para contribuir a la implantación de esas técnicas (empleo vitalicio, regímenes de remuneraciones y ascensos, etc).

Esto indica que los regímenes de gratificaciones o ascensos, cuyas características pueden depender del entorno cultural, facilitan la apreciación de la importancia de la gestión de la calidad en una organización. La cultura debe mirarse más bien como un concepto dinámico, interdependiente con las condiciones económicas, tecnológicas, sociales y políticas y con la cultura predominante, que pueden incidir en los planos macro y micro. En consecuencia, la existencia de una combinación adecuada de estas condiciones propicia el establecimiento de una "cultura de la calidad".

\section{VI}

\section{Deficiencias del mercado y programas gubernamentales}

Del análisis anterior se desprende que si bien se ha comprobado que las técnicas de gestión de la calidad promueven el desempeño productivo y competitivo de las empresas, e incluso de los países, los mecanismos del mercado no siempre son suficientes por sí solos para garantizar una difusión oportuna y generalizada de nuevas formas de gestión y organización de la producción. Por ejemplo, la influencia de los mecanismos del mercado en la difusión de las normas iso 9000 ha sido limitada y sólo las han adoptado ciertos sectores o empresas (Schuurman, 1997a). Algunos sostienen que este hecho puede ser una manifestación de la eficacia del mercado. Sin embargo, la escasa conciencia de la calidad que se observa en las PYME puede, en última instancia, afectar la competitividad y reducir las posibilidades de crecimiento económico sostenido y de generación de empleo. Por otra parle, como se indica en la sección anterior, algunos de los obstáculos que se observan a nivel macro destacan el papel que pueden desempeñar los gobiernos en la promoción de las técnicas de gestión de la calidad en un espectro más amplio de agentes económicos.

Por lo general, las fallas de los mercados se producen en el seno de las organizaciones, entre éstas, y en los mercados de factores (Lall, 1995). En el recuadro 2 se muestran los efectos y las características de varias de ellas y se ilustran las formas en que pueden intervenir los gobiernos para corregirlas. Cabe suponer que las políticas y estrategias de los gobiernos con este fin contribuyen a difundir los instrumentos de 
gestión de la calidad. Por ejemplo, los gobiernos de Brasil, los Estados Unidos, Japón, los Países Bajos y el Reino Unido han llevado a cabo estrategias de competitividad y productividad en las que incluyen dicha difusión. En el plano regional, se ha elaborado una política europea de promoción de la calidad (Comisión Europea, 1995). En los Países Bajos, el Ministerio de Asuntos Económicos estima que todos los años se pierde un $15 \%$ de la cifra de negocios por paros laborales y que las pérdidas por concepto de fallas de calidad interna ascienden a 1200 millones de dólares (Dutch Institute for Quality, 1996). Por lo tanto, bien puede valer la pena que los gobiernos inviertan en programas que persigan reducir tales perdidas.

A menudo, los programas mencionados incluyen actividades concretas de difusión de las normas iso 9000. En cuanto a políticas, en las directrices incluidas en esas normas se propone un marco bien definido, sistemático y aplicable para efectuar la gestión de la calidad y contribuir a armonizar la calidad en el comercio. Por ejemplo, en el Reino Unido un programa de financiación ayudó a las empresas pequeñas a contratar consultores externos especializados en las normas iso 9000, previendo que en el período 1988-1994 las empresas con menos de 50 empleados podían reembolsar hasta un $50 \%$ de los honorarios de los consultores. Es evidente que este programa contribuyó significativamente a que en ese país se emitiera un gran número de certificados conforme a las normas iso 9000 (cuadro 1).

\section{Programas de los gobiernos de América Latina}

Los gobiernos de los países miembros de la CEPAL enfrentan el desafío de promover el crecimiento industrial mediante un aumento acelerado de la productividad a fin de reducir las diferencias de competitividad con los países desarrollados. A este respecto, se estima que la productividad media total de los factores en América Latina es 2 a 3 veces menor que en los países desarrollados (Ramos, 1996). Los gobiernos de Brasil, Chile, Costa Rica y México también han formulado y aplicado programas para promover las técnicas de gestión de la calidad, pero éstos aún no han alcanzado la amplitud de los que se han llevado a cabo en algunos países de la Unión Europea. La excepción es Brasil, donde se puso en marcha en 1990 el Programa Brasileño de Calidad y Productividad destinado a impulsar la modernización industrial; su coordinación está a cargo de una comisión nacional del Programa y en su ejecución participa gran número de departamentos de diversos ministerios, institutos, asociaciones empresariales, empresas del Estado y del sector privado, etc. En el marco de este Programa se realizan diversas actividades encaminadas a crear más conciencia sobre la calidad, la difusión de técnicas de gestión de la calidad, al desarrollo de recursos humanos, al mejoramiento de tos servicios técnicos relacionados con la calidad, a la articulación institucional, y también a algunas actividades sectoriales (Brasil, Gobierno, 1991).

En resumen, la metodología del Programa Brasileño de Calidad y Productividad comprende:

i) El análisis del entorno económico, acompañado de una evaluación de las limitaciones sistémicas e internas que afectan la competitividad de la industria y la difusión de técnicas de gestión de la calidad;

ii) La formulación de los indicadores básicos de calidad y productividad y la definición de estándares sectoriales y globales para el país;

iii) La elaboración de un plan encaminado a sensibilizar a la sociedad y a los formadores de opinión sobre la importancia que tienen para el país las técnicas de gestión de la calidad y los costos resultantes del derroche o la baja productividad;

iv) La modernización de las instituciones que participan en la difusión de las técnicas de gestión de la calidad;

v) La difusión a grupos determinados de información de carácter general, seguida de actividades de capacitación en gran escala, y

vi) La definición de mecanismos financieros que promuevan la adopción generalizada de técnicas de gestión de la calidad (Frischtak, 1995).

Con miras a realizar una evaluación del Programa Brasileño de Calidad y Productividad se realizaron dos encuestas comparativas en 950 empresas. La primera en 1990 (año en que se implantaron las políticas de liberalización de las importaciones y se puso en marcha el Programa) y la segunda en 1993. Según los indicadores (cuadro 2), se han registrado algunos avances en el trienio mencionado, salvo en lo que se refiere a capacitación. Los datos también permiten concluir que en las empresas brasileñas aún se observa un retraso de los indicadores claves en materia de productividad media y de calidad en relación con las prácticas internacionales.

Teniendo en cuenta la poca difusión de las normas iso 9000 y las fallas del mercado que se indican en el recuadro 2, se propone que los programas de aplicación de dichas normas consideren los elementos siguientes: 
Recuadro 2

FALLAS DEL MERCADO y EJEMPLOS DE INTERVENCIÓN DE LOS GOBIERNOS CON MIRAS A DIFUNDIR TÉCNICAS DE GESTIÓN DE LA CALIDAD

\section{Fallas del mercado \\ Consecuencias}

A. En las organizaciones

B. Entre organizaciones

C. En los mercados de factores 1. Tecnología

Falta de capacidad técnica y de apoyo en esta esfera.

Uso insuficiente cíe las técnicas de gestión de la calidad en toda la cadena de producción o en los grupos de em-

presas.

difusión de la gestión de la calidad, especialmente en las PYME \{implantación insuficiente de innovaciones tecnológicas y organizativas). metrología y en investigación y desarrollo.

Falta de inversiones en el desarrollo de los recursos humanos.

\section{Programas de los gobiernos}

Características estructura de proveedores y

Falta de apoyo institucional para la difusión de innovaciones en materia de organiza-

2. Personal capacitado

3. Capital

4. Productos
Falta de idoneidad de los recursos humanos y de apoyo en esta esfera.

Acceso limitado a los recursos financieros necesarios para implementar técnicas de gestión de la calidad.

Poco reconocimiento de los regímenes de garantía de la calidad en los mercados locales e internacionales.
Falta de inversiones en

Aplicación de técnicas de gestión tradicionales; escasa conciencia en materia de calidad.

Acceso limitado a los recursos.

Capacidad insuficiente para aplicar la gestión de la calidad.

Demanda limitada de regímenes de garantía (le la calidad en la cadena de producción.

Peco desarrollo de las relaciones entre empresas. Capacidad insuficiente de la infrasubcontratistas. ción.

Difusión de información.

Facilitación del acceso a la tecnología, los conocimientos especializados y los mercados de capital (véase el tipo C).

Mejoramiento de la capacidad institucional y la estructura de apoyo.

Promoción de los vínculos institucionales y entre las empresas (véase el tipo B).

Promoción del uso de la gestión de la calidad y de garantía de la calidad en las redes de empresas.

Utilización de la capacidad de compra de las grandes organizaciones (de propiedad del Estado) para imponer regímenes preferenciales en relación con los proveedores.

Promoción de los vínculos entre las instituciones pertinentes (académicas, económicas, laborales, exportadoras, tecnológicas, etc),

Mejoramiento de la capacidad de los institutos de normalización y metrología. Promoción de la investigación y desarrollo pertinentes.

Fomento del desarrollo de los recursos humanos pertinentes (académicos, auditores, consultores).

Préstamos comerciales no viables (alto riesgo y tasas de interés elevadas).

Falta de armonización y normalización institucional en materia de calidad.

Establecimiento de regímenes de garantía de calidad reconocidos por los socios comerciales (como los regímenes de registro por auditores y consultores).

Fuente: Véase una descripción pormenorizada de los programas de los gobiernos en Schuurman, 1997b. 
CUADRO 2

Brasil: Progresión de los indicadores relativos a la gestión tota! de la calidad ${ }^{3}$

\begin{tabular}{|c|c|c|c|c|}
\hline Indicador & $\begin{array}{c}\text { Brasil } \\
1990\end{array}$ & $\begin{array}{c}\text { Brasil } \\
(993 \\
\end{array}$ & $\begin{array}{l}\text { Europa y } \\
\text { Estados Unidos }\end{array}$ & Japón \\
\hline Rechazos (partes defectuosas por millón) & $23000-28000$ & $11000-15000$ & 200 & 10 \\
\hline Reprocesamiento (\% de productos que se reprocesan) & 30 & $12-20$ & 2 & 0.001 \\
\hline Gastos en asistencia técnica (\% de las ventas) & 2.7 & 2.0 & Of & $<0.05$ \\
\hline Plazo medio de entrega (en días) & 35 & 20 & $2-4$ & 2 \\
\hline Tamaño medio de las partidas & 1000 & $100-250$ & $20-50$ & $1-10$ \\
\hline Rotación del inventario (número de veces por año) & 8 & 8-14 & $60-70$ & $150-200$ \\
\hline Tiempo de instalación (en minutos) & 80 & $30-40$ & 10 & 5 \\
\hline $\begin{array}{l}\text { Tiempo de parada de las máquinas } \\
\text { (expresado como porcentaje del tiempo muerto) }\end{array}$ & 40 & 21 & $15-20$ & $5-8$ \\
\hline $\begin{array}{l}\text { Gastos en investigación y desarrollo } \\
\text { (como \% de las ventas) }\end{array}$ & $<\mathrm{i}$ & $1-2$ & $3-5$ & $8-12$ \\
\hline $\begin{array}{l}\text { Capacitación } \\
\text { (\% de las horas de trabajo, por empleado y por año) }\end{array}$ & $<\mathrm{t}$ & $<1$ & $5-7$ & 10 \\
\hline Niveles jerárquicos & $10-12$ & $4-8$ & 7 & 3 \\
\hline
\end{tabular}

Fuente: IMAM Consultaría Ltd., citado en Frischlak, 1995.

a Evaluación del Programa Brasilüfio de Calidad y Productividad de 1991 a 1994.

i) Difusión de información a fin de crear conciencia sobre la importancia de la calidad en una amplia gama de agentes económicos y modificar la percepción tradicional de la gestión de la calidad;

ii) Apoyo a las empresas, facilitando su acceso a los mercados de factores vinculados con los recursos técnicos, de capital y humanos;

iii) Apoyo para la aplicación y certificación de las normas iso 9000 en las redes de empresas, a fin de promover la difusión de los conceptos de garantía de la calidad en las cadenas de producción y en los marcos institucionales, $\mathrm{y}$

iv) Consolidación, a nivel nacional, de ¡a estructura institucional de apoyo a la aplicación de las normas iso 9000 y la certificación y reconocimiento internacionales pertinentes (Schuurman, 1997b).

De la evaluación de las actividades del programa de promoción de las normas iso 9000, con arreglo a los elementos del programa ya enumerados, ${ }^{12}$ en algunos países de América Latina (recuadro 3) puede concluirse que:

i) Los organismos de gobierno de casi todos los países analizados han prestado asistencia a las actividades vinculadas con la difusión de información sobre las normas iso 9000 , pero hasta ahora no ha habido una difusión generalizada de los sistemas de calidad certificados con arreglo a dichas normas.

12 Para más información y referencias sobre el tema analizado en la presente sección, véase Sehuurmun (1997a y 1997b). ii) Varios gobiernos han reconocido la existencia de fallas del mercado en los factores relacionados con el capital y los recursos humanos y han establecido incentivos económicos, líneas de crédito y actividades de capacitación y apoyo técnico encaminados a fomentar la aplicación de las normas iso 9000 y las certificaciones pertinentes.

iii) Los gobiernos de Brasil y Chile han iniciado y apoyado proyectos que tienen por objeto promover el uso de técnicas de gestión de la calidad en determinados grupos de empresas que integran la cadena de la producción. Por ejemplo, los proyectos del Gobierno de Chile apuntan a organizar actividades vinculadas con la garantía de la calidad en la red de proveedores y subcontratistas de una gran empresa, creando de este modo condiciones que beneficien a ambos. En Brasil, las grandes empresas y organizaciones de los sectores público y privado han aprovechado su capacidad de compra para implantar regímenes preferenciales que benefician a los proveedores y contratistas certificados con arreglo a las normas iso 9000, y

iv) La mayoría de los gobiernos están desarrollando o ya han establecido regímenes nacionales de acreditación y certificación con arreglo a las normas iso 9000.

En resumen, los gobiernos de la región parecen cada vez más inclinados a establecer programas que promuevan y apoyen la difusión de las normas iso 9000 
Recuadro 3

AMÉRICA LATINA: RESUMEN DE LOS PROGRAMAS NACIONALES DE DIFUSIÓN DE LAS NORMAS ISO 9000 EN ALGUNOS PAÍSfiS ${ }^{: /}$

\begin{tabular}{|c|c|c|c|c|}
\hline \multirow[t]{2}{*}{ País } & \multirow{2}{*}{$\begin{array}{l}\text { Programa o documento } \\
\text { de políticas oficiales } \\
\text { sobre la calidad y la } \\
\text { competitividad }\end{array}$} & \multirow[t]{2}{*}{$\begin{array}{c}\text { Difusión de } \\
\text { información sobre las } \\
\text { normas iso } 9000\end{array}$} & \multicolumn{2}{|c|}{$\begin{array}{c}\text { Apoyo para la aplicación de } \\
\text { sistemas de calidad e } \\
\text { institucionalización_relacionada } \\
\end{array}$} \\
\hline & & & $\begin{array}{l}\text { En la pequeña y } \\
\text { mediana empresa }\end{array}$ & $\begin{array}{l}\text { En los grupos } \\
\text { de empresas }\end{array}$ \\
\hline Argentina & $(-)$ & Sí & Sí & $(-)$ \\
\hline Brasil & Sí & Sí & Sí & Sí \\
\hline Bolivia & $(-)$ & $(-)$ & $(-)$ & $(-)$ \\
\hline Chile & Sí & Sí & Sí & Sí \\
\hline Colombia & $(-)$ & Sí & Sí & $(-)$ \\
\hline Costa Rica & Sí & $(-)$ & $(-)$ & $(-)$ \\
\hline Cuba & $(-)$ & Sí & $(-)$ & $\mathbf{H}$ \\
\hline México & Sí & Sí & Sí & $(-)$ \\
\hline Perú & $(-)$ & Sí & $\{-)$ & $(-)$ \\
\hline \multicolumn{5}{|c|}{ Fuente: Información reunida por la autora en diversas misiones. } \\
\hline \multicolumn{5}{|c|}{$\begin{array}{l}\text { : El símboio (-) significa que la información no está disponible o no se encontró y que, en consecuencia, puede } \\
\text { haber programas de ese tipo. }\end{array}$} \\
\hline
\end{tabular}

y las técnicas de gestión de la calidad. Tal tendencia demuestra que estos gobiernos reconocen la existencia de fallas del mercado derivadas de la falta de difusión de las innovaciones en materia de gestión de la calidad en las organizaciones y los sectores económi- cos y que esta difusión es conveniente desde el punto de vista de los intereses nacionales. Al respecto, la calidad desempeñará un papel cada vez más importante en lo que toca a los objetivos de desarrollo social y económico de los países latinoamericanos.

\section{VII}

\section{Observaciones finales}

Las ventajas que puede traer consigo la incorporación de innovaciones en materia de gestión de la calidad a las estrategias de competitividad de los gobiernos de América Latina se resumen a continuación.

Los temas relacionados con la calidad, como los regímenes de gestión total de la calidad y de garantía de ella, favorecen la competitividad de los sectores económicos e incluso de los países que compiten hoy en los mercados mundiales.

Se puede vincular una gama de técnicas de gestión de la calidad con los parámetros que definen la competitividad de las empresas (factores de la competencia relacionados con la satisfacción del cliente) y el mejoramiento continuo de los procesos.

Varios estudios indican que los costos de aplicar las técnicas de gestión de la calidad son menores que los costos que derivan de no aplicarlas. Por ejemplo, los costos resultantes de los defectos de calidad pueden alcanzar hasta el $25 \%$ del total del volumen de negocios de una empresa, mientras que el costo de evitar dichos defectos se estima en $7 \%$ de esa cifra.

En América Latina hay poca conciencia de la ca- 
liclad y la aplicación de técnicas de gestión de la calidad es limitada. Si se intensifica la difusión de los conceptos de dicha gestión se contribuirá a reducir la disparidad existente entre los niveles de competitividad y productividad de la región y del resto del mundo.

Asimismo, la aplicación de técnicas de gestión de la calidad enfrenta ciertos obstáculos. Esto ocurre porque los mecanismos del mercado son incapaces de difundir adecuadamente tales técnicas, especialmente en las PYMF.. LOS gobiernos pueden optar por corregir esas fallas del mercado incorporando los temas relativos a la calidad en sus programas destinados a mejorar la productividad. Por ejemplo, el Gobierno de Bra- sil, a través del Programa Brasileño de Calidad y Productividad, ha contribuido a mejorar el desempeño comercial de varios sectores de la economía nacional (recuadro 3).

El hecho de que otros gobiernos de la región estén adoptando medidas similares, promoviendo por ejemplo la aplicación de sistemas de gestión de la calidad (iso 9000), permite suponer que estos temas desempeñarán un papel cada vez más importante en relación con los objetivos de desarrollo social y económico de América Latina.

(Traducido del inglés)

\section{Bibliografía}

American Quality Foundation (199I): 'The Definitive Study of Best International Quality Management Practices, Cleveland, Ohio, Ernst \& Young.

Asociación Brasileña de Normas Técnicas (1996): A SEBRAE survey demonstrates iso 9000 implementation difficulties in Brazilian companies, Revista ABNT, Rio de Janeiro, marzo.

Brache, A. (1988): The (hree levels of quality, Quality Progress, octubre.

Brasil, Gobierno (1991): Programma Brasileira da Qualidade e Produclividacle, Brasilia.

Burnt, D. (1900): Cooperation with suppliers, Harvard Holland Review, $\mathrm{N}^{\circ}$ 2, Países Bajos.

Champy, J. (1995): Reengineering Management, Nueva York, Harper Collins.

Comisión Europea (1995): Working document on a European quality promotion policy. Directorate-General III, Bruselas.

Dutch Institute for Quality (1996): De stand van zaken van intégrale kwaliteitszorg in Nederhind, Den Bosch.

Henry, A. (1993): Human resources and (he diffusion and adaptation of new quality methods in Brazilian manufacturing, IDS Research Report, $\mathrm{N}^{\circ}$ 24, Brighton, University of Sussex, Institute of Development Studies (IDS).

(1995): Quality and productivity in the competitive strategies of Brazilian industrial enterprises, World Development, vol. 23, $\mathrm{N}^{\circ} \mathrm{I}$, Oxford, Reino Unido, Elsevier Science Ltd.

Foro Económico Mundial, Instituto Internacional para el Desarrollo de la Capacidad de Gestión (1995J." The World Competitiveness Repon, 1995, Lausanne, Suiza.

Frischlak, C. (1995): The Brazilian Industry's Productive Revolution and the Dissemination of the ISO 9000 Standards, Santiago de Chile, Comisión Económica para América Latina y el Caribe (CEPAL).

Hammer, M. y J. Champy (1993): Reengineering the Corporation, Nueva York, Harper Collins.

Humphrey, J. (1993): Quality and productivity in industry: New strategies in developing countries, IDS Bulletin, vol. 24, $\mathrm{N}^{\circ} 2$, Brighton, University of Sussex, IDS.

(1995): Introduction of the editor, World Development, vol. $23, \mathrm{~N}^{\mathrm{c}}$ I, Oxford, Reino Unido, Elsevier Science Ltd.

iNMETROMiCT (Instituto Nacional de Metrología, Normalización y Calidad Industrial/Ministério da Indústria, do Comercio e do Turismo) (1996): Brasil e a Certificacion ISO 9000, Rio de Janeiro. iso (Organización Internacional de Normalización) (;993): Vision 2000. A Strategy for International Standards' Implementation in the Quality Arena During the 1990s, Ginebra.

ISO 9000 News (1996): The Mobil Survey (Fifth Cycle) of iso 9000 and Environmental Certificates Awarded Worldwide, $\mathrm{N}^{\circ} 6$, Ginebra, Mobil Europe Ltd., agosto.

ISO/UNCTAD/GATT (Organización Internacional de Normalización/ Conferencia de las Naciones Unidas sobre Comercio y Desarrollo/Acuerdo General sobre Aranceles Aduaneros y Comercio) (1993): iso 9000 Quality Management Systems: Guidelines for Enterprises in Developing Countries, Ginebra.

Kaplinski, R. (1993): Notes on the implementation of quality and productivity programmes in sectors of Brazilian industry, Quality and productivity in Industry: New strategies in developing countries, IDS Bulletin, vol. 24, $\mathrm{N}^{\circ} 2$, Brighton, University of Sussex, IDS.

(1995): Technique and system: The spread of Japanese management techniques to developing countries, World Development, vol. 23, $\mathrm{N}^{\circ}$ 1, Oxford, Reino Unido, Elsevier Science Ltd., enero.

KID (Kwalitertsdieist Foundation for Quality Services) (1996): Betere resultation door TQM, Magazines Speciftek, Rotterdam, septiembre.

Lall, S. (1995): Governments and industrialization: The role of interventions in the 1990s, ECLAC/IDRC-UNU/INTECU Conference on Productivity: Technical change and National Innovation Systems in Latin America in the 1990s, versión preliminar, Santiago de Chile, CECAL, agosto

Leñero, J. (1995): Reingeniería: Gerencia para la globalización, Revista Rumbo, San José, Costa Rica.

Maas, J. (1992): Innovarte en beheersing in balans, Sigma Magazi$n e, \mathrm{~N}^{\circ} 3$.

MacDonald, J. (1995): Together TQM and business process rcengineering are winners, TQM Magazine, vol. $7, \mathrm{~N}^{\circ} 3$.

Nakamura, T. (1992): Dc ontwikkeling van het kwaliteitskostensystem, Sigma Magazine, vol. 18, $\mathrm{N}^{\circ} 5$.

OCDE (Organización de Cooperación y Desarrollo Económicos) (1993): Small and Medium-Sized Enterprises: Technology and Competitiveness, París.

Pandora, D. (1989): Quality Management as a Competitiveness Tool, Delft, Países Bajos, Technical University Deltf.

Porter, M. (J980): Competitive Strategy: Techniques for Analysing Industries and Competitors, Nueva York, Free Press. 
Q Review (1993): ISO 9000 boosts industry performance says market survey, News from Lloyd's Register Quality Assurance Ltd., Londres, noviembre.

Ramos, A. (1995): Hacia la calidad total: la difusión de las normas ;SO 9000 en la industria argentina, Buenos Aires, Oficina de la CEPAL en Buenos Aires.

Ramos, J. (1996): Política industrial y competitividad en economías abiertas, Desarrollo productivo, $N^{\circ} 34$, LC/G. 1928, Santiago de Chile, CEPAL.

Rauter, R. (1992): Calidad con productividad; el desafío de los años noventa y del nuevo milenio, LC/R.1198, Santiago de Chile, CEPAL.

Reinecke, R. (1996): Innovation, flexibilization and social exclusion in advanced developing countries: General considerations and empirical research, Santiago de Chile, Organización Internacional del Trabajo (OIT), mimen.

Shaiken, H, (1994): Advanced manufacturing and Mexico: A new international division of labor?, Latin American Research Review, vol. 29, $\mathrm{N}^{\circ}$ 2, Chapel Hill, North Carolina, Latin American Studies Association (LASA).

Schuurman, H. (1997a); Quality Management and Competitiveness: The Diffusion of the ISO 9000 Standards in Latin America and
Recommendations for Government Strategies, Santiago de Chile, CEPAL.

(1997b): Quality Management, ISO 9000 and Government Programmes, Santiago de Chile, CEPAL

Spitzer, R. (1993): Valuing TOM through rigorous financial analysis, Quality Progress, julio.

TUV Reinland Chile (1995): Correspondence with C. Wagener, Santiago de Chile, mimeo.

Tedinovation (1994): The Brazilian National Quality Award; Sharing some best practices of the winner in 1993, vol. 14, $\mathrm{N}^{\circ} 10$, Amsterdam, Países Bajos, Elsevier Science Publishers, B.v.

Van de Broek, H. (1991): Algemene Indrukken uit Kwaaliteilskundige Onderzoeken, Países Bajos, Wolters Noordhof.

Vispo, A. (1994)/ Tecnologías de organización y estrategias competitivas, Buenos Aires, Oficina de la CEPAL en Buenos Aires.

Wíldschut, E. (1993): Time Based Competition: Strategic Advantage for Shorter Enterprise Processes, Países Bajos, Kluwer Deventer.

Winchelt, W. (1987): Quality cost analysis: Extend the benefits, Quality Progress, septiembre.

Zairí, M. (1996): Benchmarking: A process-driven tool for quality improvement, TQM Magazines, vol. 7, $\mathrm{N}^{\circ} 3$. 